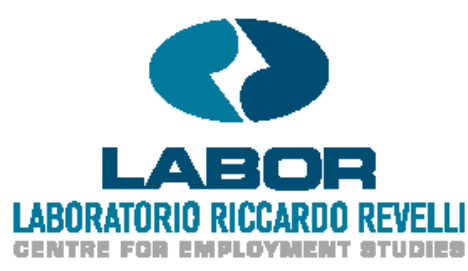

Working Paper no. 84

On Polarization and Mobility: A look at polarization in the wagecareer profile in I taly

\author{
A. Poggi, \\ LABORatorio Revelli, \\ Collegio Carlo Alberto \\ J. Silber \\ Department of Economics, \\ Bar-Ilan University
}




\section{On Polarization ${ }^{1}$ and Mobility:}

\section{A look at polarization in the wage-career profile in Italy}

Ambra Poggi

LABORatorio Revelli,

Collegio Carlo Alberto

Via Real Collegio 30

Moncalieri, Torino, Italy
Jacques Silber

Department of Economics,

Bar-Ilan University, 52900 Ramat-Gan,

Israel.

1 This research was made possible by a grant (number 936/05) from the Israel Science Foundation. 


\begin{abstract}
This paper attempts to combine the analysis of wage (income) polarization with that of wage (income) mobility. Using the polarization index $P_{G}$ recently proposed by Deutsch et al. (2007) it shows that, when taking the identity of the individuals into account (working with panel data), a distinction can be made between a change over time in polarization that is the consequence of "structural mobility" (change over time in the overall, between and within groups inequality) and a change in polarization that is the sole consequence of "exchange mobility" (changes over time in the ranks of the individuals).

This approach is then applied to the 1985-2003 Work Histories Italian Panel (WHIP), an employeremployee linked panel database developed by the Italian Social Security administrative sources. The empirical investigation attempts to improve our understanding of labor market segmentation in Italy, whether the groups are defined on the basis of the individual wages or when they are derived from other criteria such as white versus blue collar workers.
\end{abstract}

Key Words: exchange mobility - Italy - labor market segmentation - polarization -structural mobility - wage inequality

J.E.L. Classification: D31 - J31 


\section{Introduction}

As is by now well-known the concept of labor market segmentation introduced by Piore and Doeringer (1971) is based on the idea that in the labor market there are mainly two non-competing groups corresponding respectively to what has been called the primary and the secondary sector. The primary sector generally includes mainly higher-status and better-paid jobs and in this market skills and educational credentials play an important role. In the secondary sector jobs are usually low-skilled and most of the time require little training. Wages are low and hence there is a high level of labor turnover. Job mobility between the two sectors is assumed to be normally quite limited, mainly because workers in the secondary sector are trapped there unless they manage to increase their educational or skill level. The secondary sector is also characterized by higher levels of underemployment and unemployment.

This gross description of the labor market cannot however be simply applied to all economies, even if one limits oneself to Western countries. As argued by Contini (2002) it seems that "upward and downward earning mobility of the relatively better offfraction of the work-force is higher in the USA than in the European countries. Labor market segmentation in the lower tail of the earning distribution is higher in the USA than in continental Europe. The Scandinavian countries are even more distant from the USA...".

Empirical studies of the phenomenon of labor market segmentation have generally emphasized the increasing level of pay inequality but have also checked whether low skilled individuals are "trapped" in the lower part of the earnings distribution or whether there is a relatively high level of mobility so that a low pay may be a temporary phenomenon. Whereas the desire to focus on earning mobility rather than on earning inequality is certainly laudable, such an effort may not be sufficient to obtain a complete picture of the situation in the labor market. Recent work on the concept of polarization and its implications concerning the possibility of conflict has emphasized the idea that the degree of polarization should be an increasing function of earning differences between groups but a decreasing function of earning differences within groups.

The purpose of this paper is first to propose a methodology allowing to combine information on polarization and on mobility, second to give an empirical illustration 
based on quite unique data on the Italian labor market. The paper is organized as follows. Section 2 describes the methology while section presents the results of en empirical investigation based on Italian data. The paper ends by emphasizing some preliminary conclusions which could be drawn from such type of analysis.

\section{Methodological framework}

In a recent note Deutsch et al. (2007) proposed a new index of bipolarization defined as

$P_{G}=\left(G_{B}-G_{W}\right) / G$

where $G_{B}, G_{W}$ and $G$ refer respectively to the between groups, the within groups and the overall Gini index (for the whole distribution). Note that this formulation assumed that there were only two groups and of equal size, the "poor" and the "rich" who are respectively those individuals earning less and more than the median income.

In another paper Deutsch and Silber (2007) showed that this index $P_{G}$ could be extended to the case where there more than two groups and where the income distributions of these groups overlap.

Let us now assume that this index $P_{G}$ is computed at two different periods, times 0 and 1, in which its value will be expressed as $P_{G 0}$ and $P_{G 1}$. The change $\Delta P_{G}$ in polarization between times 0 and 1 may therefore be written as

$\Delta P_{G}=\left(P_{G 1}-P_{G 0}\right)=\left(\left(G_{B 1}-G_{W 1}\right) / G_{1}\right)-\left(\left(G_{B 0}-G_{W 0}\right) / G_{0}\right)$

where $G_{B t}, G_{W t}$ and $G_{t}$ refer to the between groups, the within groups and the overall

Gini indices at time $t(t=0$ or 1$)$.

Expression (2) may also be written as

$\Delta P_{G}=f\left(\Delta G_{B}, \Delta G_{W}, \Delta G\right)$ 
where $\Delta G_{B}, \Delta G_{W}$ and $\Delta G$ refer respectively to the change in the between groups, the within groups and in the overall Gini index that took place between times 0 and 1 .

The measure $\Delta P_{G}$ is however an anonymous measure of the overall change in polarization between times 0 and 1 , since it completely ignores the identity of the individuals. It is simply derived from the computation of the degree of polarization at both periods. If, for example, we divide the population in two income groups, those with an income below and above the median income, it is very likely that the identity of the individuals having an income below the median income will be not exactly be the same at both periods, because there certainly will have been some degree of income mobility between times 0 and 1 .

Let us therefore define as $G_{B t s}, G_{W t s}$ and $G_{t s}$ the between groups, within groups and total Gini indices, assuming these indices are computed on the basis of the income the various individuals would have received at time $t$, had their rank been that they had at time s. Using these notations the indices $G_{B 0}, G_{W 0}$ and $G_{0}$ in (2) would be expressed as $G_{B 00}, G_{W 00}$ and $G_{00}$ and similarly the indices $G_{B 1}, G_{W 1}$ and $G_{1}$ in (2) would be expressed as $G_{B 11}, G_{W 11}$ and $G_{11}$. Let us also call $P_{G t s}$ the value of the polarization index which is obtained when it is based on the indices $G_{B t s}, G_{W t s}$ and $G_{t s}$. The indices $P_{G 1}$ and $P_{G 0}$ in (2) will therefore from now on be expressed as $P_{G 11}$ and $P_{G 00}$.

But we could also compute a polarization index $P_{G 10}$ which would measure the degree of polarization that would be obtained on the basis of the incomes at time 1, assuming the individuals kept the rank they had at time 0 . Similarly a polarization index $P_{G 01}$ would measure the degree of polarization that would be obtained on the basis of the incomes at time 0 , assuming the rank of the individuals at time 0 was that they had time 1 .

We may therefore want to give an alternative definition of the change in polarization between times 0 and 1, one that would not ignore the identity of the individuals and would be expressed, for example, as

$\Delta^{\prime} P_{G}=\left(P_{G 10}-P_{G 00}\right)=\left(\left(G_{B 10}-G_{W 10}\right) / G_{10}\right)-\left(\left(G_{B 00}-G_{W 00}\right) / G_{00}\right)$

Another possibility is to define such a non anonymous change in polarization as 
$\Delta^{\prime \prime} P_{G}=\left(P_{G 11}-P_{G 01}\right)=\left(\left(G_{B 11}-G_{W 11}\right) / G_{11}\right)-\left(\left(G_{B 01}-G_{W 01}\right) / G_{01}\right)$

At this stage let us use, for example, expression (5) and rewrite it as

$$
\begin{aligned}
\Delta^{\prime \prime} P_{G} & =\left(P_{G 11}-P_{G 01}\right)=\left[\left(\left(G_{B 11}-G_{W 11}\right) / G_{11}\right)-\left(\left(G_{B 00}-G_{W 00}\right) / G_{00}\right)\right] \\
& +\left[\left(\left(G_{B 00}-G_{W 00}\right) / G_{00}\right)-\left(\left(G_{B 01}-G_{W 01}\right) / G_{01}\right)\right]
\end{aligned}
$$

Note that the first element on the R.H.S. of (6) measures the change in polarization that is obtained under the assumption of anonymity. The second element on the R.H.S. of (6) computes the hypothetical change in polarization that is obtained when using the same incomes (those the individuals receive at time 0) but the first time these individuals are assumed to have the ranking they indeed had at time 0 , the second the ranking they had at time 1 .

Similarly $\Delta^{\prime} P_{G}$ in (4) may be also expressed as

$$
\begin{aligned}
\Delta^{\prime \prime} P_{G} & =\left(P_{G 10}-P_{G 00}\right)=\left[\left(\left(G_{B 10}-G_{W 10}\right) / G_{10}\right)-\left(\left(G_{B 11}-G_{W 11}\right) / G_{11}\right)\right] \\
& +\left[\left(\left(G_{B 11}-G_{W 11}\right) / G_{11}\right)-\left(\left(G_{B 00}-G_{W 00}\right) / G_{00}\right)\right]
\end{aligned}
$$

Note that this time the first element on the R.H.S. of (7) computes the hypothetical change in polarization that is obtained when using the same incomes (those the individuals receive at time 1) but the first time these individuals are assumed to have the ranking they indeed had at time 0 , the second the ranking they had at time 1 . It is easy to observe that the second element on the R.H.S. of (7) measures the change in polarization that is obtained under the assumption of anonymity.

Clearly we can also combine (6) and (7) to derive an average $\Delta^{\prime \prime \prime} P_{G}$ which would then be expressed as

$$
\begin{aligned}
\Delta^{\prime \prime \prime} P_{G}= & {\left[\left(\left(G_{B 11}-G_{W 11}\right) / G_{11}\right)-\left(\left(G_{B 00}-G_{W 00}\right) / G_{00}\right)\right] } \\
+ & (1 / 2)\left\{\left[\left(\left(G_{B 00}-G_{W 00}\right) / G_{00}\right)-\left(\left(G_{B 01}-G_{W 01}\right) / G_{01}\right)\right]\right. \\
& +\left[\left(\left(G_{B 10}-G_{W 10}\right) / G_{10}\right)-\left(\left(G_{B 11}-G_{W 11}\right) / G_{11}\right)\right]
\end{aligned}
$$


The first expression on the R.H.S. measures again the change in polarization, assuming anonymity. The second element on the R.H.S. of (8) computes the hypothetical change in polarization that is obtained when using the same incomes, that is, either those the individuals receive at time 1 or those they receive at time 0 , but in each case these individuals are assumed to have first the ranking they indeed had at time 0 , second the one they had at time 1. It is in fact easy to show that (8) is the expression one would have derived had one applied the by now quite famous so-called Shapley decomposition.

Let us now be more explicit about the way to compute expressions like $G_{B 01}, G_{B 10}, G_{W 01}, G_{W 10}, G_{01}$ and $G_{10}$. We know (see, Silber, 1989) that the between groups Gini index $G_{B}$ may be written as

$G_{B}=f^{\prime} G s$

where $f^{\prime}$ is a row vector giving the shares of the various groups in the total population, the groups being ranked by decreasing values of the average incomes of the groups.

Similarly $s$ is a column vector giving the shares of the various groups in total income, the groups being ranked by decreasing values of their average incomes.

Finally, assuming there are $K$ groups, $G$ is a $K$ by $K$ square matrix called G-matrix (see, Silber, 1989) whose typical element $g_{i j}$ is equal to 0 if $i=j$, to -1 if $j \succ i$ and to +1 if $i \succ j$.

Therefore in defining $G_{B 01}$ we will rank the groups in $f^{\prime}$ and $s$ by their decreasing average incomes at time 1 but will give each group its income share at time 0 . Note that since we work with non anonymous groups, there will evidently be no difference between the population shares at time 0 and 1 .

Similarly in defining $G_{B 10}$ we will rank the groups in $f^{\prime}$ and $s$ by their decreasing average incomes at time 0 but will give each group its income share at time 1 .

To compute the within groups inequality $G_{W t s}$ we have to remember that the within groups Gini inequality index is defined as 
$G_{W}=\sum_{k=1}^{K} f_{k} w_{k} G_{k}$

where $f_{k}, w_{k}$ and $G_{k}$ represent respectively the population shares, the income shares and the Gini index of group $k$. Note that $G_{k}$ is defined as

$G_{k}=f_{k}^{\prime} G s_{k}$

where ${f^{\prime}}_{k}$ is a 1 by $n_{k}$ row vector of elements each equal to $\left(1 / n_{k}\right), n_{k}$ being the number of individuals in group $k$. Similarly $s_{k}$ is a $n_{k}$ by one column vector giving the share of each individual belonging to group $k$ in the total income of this group. Finally $G_{k}$ is a $n_{k}$ by $n_{k}$ G-matrix, the latter having been defined previously.

Therefore in defining $G_{W 01}$ we assume that, in applying the expression given in (10), the population and income shares $f_{k}$ and $w_{k}$ are those at time 0 . In computing $G_{k}$ however we rank the individuals (in the vectors $f^{\prime}{ }_{k}$ and $s_{k}$ ) according to their rank at time 1 but give these individuals their income at time 0 .

Similarly in defining $G_{W 10}$ we assume that in applying the expression given in (10), the population and income shares $f_{k}$ and $w_{k}$ are those at time 1 . In computing $G_{k}$ however we rank the individuals (in the vectors $f^{\prime}{ }_{k}$ and $s_{k}$ ) according to their rank at time 0 but give these individuals their income at time 1.

Finally in computing the overall Gini indices $G_{t s}$ we apply again the general formulation for the Gini index $I_{G}$, that is,

$I_{G}=e^{\prime} G s$

where $e^{\prime}$ is a 1 by $n$ row vector of $n$ elements each equal to $(1 / n), n$ being the overall size of the total population (including all the subgroups) and $s$ is a $n$ by 1 column vector whose elements are the shares of the individuals in total income. Note that the elements of both $e^{\prime}$ and $s$ are ranked by decreasing individual income, no matter the group to which each individual belongs. $G$ in (12) is evidently a $n$ by $n$ G-matrix. 
Therefore in defining a Gini index $G_{01}$ we assume that the individuals are ranked (in $f^{\prime}$ and $s$ in (12) ) according to their rank at time 1 but the individuals are given their income share at time 0 . Similarly in defining a Gini index $G_{10}$ we assume that the individuals are ranked (in $f^{\prime}$ and $s$ in (12) ) according to their rank at time 0 but the individuals are given their income share at time 1.

Note that the formulation for the non anonymous change in polarization which is given in (8) applies to the cases of both non-overlapping and overlapping groups (see, Deutsch and Silber, 2008b). In the case of non-overlapping groups the overall Gini index is equal to the sum of the between and within groups Gini indices. In the case of overlapping groups the overall Gini index includes a third element which measures in fact the degree of overlap between the income distributions of the various groups (see, Silber, 1989).

\section{An Empirical Illustration}

\section{The data}

We use the 1985-2003 Work Histories Italian Panel (WHIP), an employer-employee linked panel database developed by Italian Social Security administrative sources. For its institutional purposes, the Italian Social Security Administration collects data on both individual employees and firms (employers). The reference population is made up of all the people - Italian and foreign - who have worked in Italy even if for only part of their working career. The entire private sector is covered (about 10 million employees and 1.2 million firms per year) and a large representative sample has been extracted from this population. The WHIP does not include information about workers in the agricultural sector and the public administration. It includes information about the workers' age, professional category, sector, dates at which employment spells start and end, the type of contract held by the worker, the annual wages, the number of the days worked per year, etc... Note that in the administrative archives any information which is not especially of interest to the Italian Social Security Administration (e.g. the worker's level of education) is not collected. On the other hand, the degree of coverage and of accuracy of the administrative archives cannot be found in any other Italian dataset. Also note that we do not have any attrition problems because, once a certain group of 
individuals has been selected, it is possible to follow them over the entire period under investigation.

We selected individuals born in 1970-2 and observed these individuals when they entered the labor market. We focus on individuals who become employees in the private sector (agriculture is excluded). ${ }^{2}$ About $80 \%$ of these individuals entering the labor market are less than 28 years old and they can be followed over a 5-year horizon. Since we wish to investigate their wage-career profiles we need to observe individual wages at several points in time. We therefore restrict the sample to individuals that also worked three and five years after having entered the labor market. Our sample is composed of 8311 individuals, $64 \%$ of them being males and $36 \%$ females.

\section{Wages distribution and inequality}

We find that on average real daily wages ${ }^{3}$ increase as the workers' career becomes longer (see Table 1). In this context, the workers' career may be interpreted as the length of time individuals spend in the labor market or, equivalently, as potential experience / seniority. In fact, we admit the possibility that young workers experience unemployment spells (shorter than 2 years) because of the difficulty of finding the right matches and of long searching times. The real daily wages are, on average, about 31 euros at year 2000 prices at entry (about 800 euros monthly) and they grow by about $45 \%$ during the period of 5 years. Figure 1 puts in evidence some important aspects of the earning distribution in Italy at the time of entry in the labor market and three and five years later. It gives a graphical representation of the density function of the wage distribution, derived from the kernel estimation method. The height of the curve indicates the concentration of people at different points along the wage scale while the area under the curve between two wages levels shows the share of the population with wages between those two levels. The location, spread and mode of the wage distribution indicate respectively the real wage levels, wage inequality and wage clumping. The curves in Figure 1a are drawn on the basis of the whole sample. The density function

\footnotetext{
${ }^{2}$ No self-employed or atypical workers ("parasubordinati") are included in the sample: the main reason is that for such individuals we would have information about the length of their working spells but not about their job attributes and for our study we need the latter information.

${ }^{3}$ Daily wages are computed by dividing the gross annual wages (before taxes and inclusive of overtime and bonuses) by the number of days he/she got paid for during the year. Real wages are computed at year 2000 prices.
} 
corresponding to wage at entry shows that the vast majority of the population has low real daily wages. The left hand side of the curve appears to be multimodal. When looking at the density function of wages three years after entry, we note a shift of the curve to the right. The curve becomes also flatter at very low wages (even though the clumping does not disappear completely). Both observations indicate that there was an overall increase in wages as well as probably a decrease in inequality. Finally the density function of the wages five years after entry shows a further shift of the curve to the right and a "squashing up" of the curve which correspond to an additional increase in wages (probably due to experience/seniority) and a decrease in inequality. The density appears now to be relatively smooth and unimodal: at both ends of the density function, the curve is now relatively thin, an indication that there are now fewer people with very low or very high wages. Note finally that all three curves are strongly asymmetrical towards the right, this implying that the proportion of employees earning more than the modal wage is larger than that earning less.

In short Figure 1a (this is even more evident when looking at the data of Table 2) indicates that the inequality of earnings is lower five years after entry than at entry. The Gini index decreases by $28 \%$, a consequence of the fact that the original multimodal wage distribution characterized by a large group of very low paid individuals became a unimodal distribution with fewer individuals with a low or a high pay.

To interpret these findings, we need to understand the characteristics of the process of entry into the labor market in Italy. It turns out that only $36 \%$ of the individuals in our sample are hired by standard contracts, the rest (64\%) being hired on the basis of specific temporary or fixed term contracts providing apprenticeship and training components (called hereafter "youth contracts") under the name of apprenticeship contracts or training-at-work contracts (Contratti di Formazione e Lavoro, CFL). These contracts should be considered as an important policy tool to combat youth unemployment and ease the insertion of youth into the labor market. The goals of such institutional arrangements are to hire first-time job seekers and train young workers. These contracts, in principle, offer a combination of work and training allowing workers to learn and accumulate experience. The CFL contracts are aimed at individuals aged 15-29 with at least upper secondary education and their duration is 1 or 2 years. Apprenticeship contracts are aimed at individuals aged 16-24 and their maximum duration is 4 years (while the minimum duration is 18 months). Incentives offered to firms to hire on the basis of such contracts are mainly lower social security 
contributions and, in the case of apprenticeship contracts, the possibility to pay lower wages. CFL contracts offer also incentives to firms to transform such contracts into ordinary contacts.

In Figure $1 b$ we have drawn the density functions of the wage distributions when individuals with apprenticeship contracts are excluded. ${ }^{4}$ The density at the time of entry into the labor market appears to be relatively smooth and unimodal and strongly asymmetrical towards the right: at the both ends of the density function, the curve is relatively thin indicating that there are few people with very low or high wages. One should note that the proportion of individuals with a low pay is much smaller than the one observed in Figure 1a (the density referring to the entire sample, including apprenticeship contracts). It thus appears that individuals may enter into the labor market by two channels: standard contracts (and CFL) characterized by high wages and apprenticeship contracts characterized by low wages (see also Table 1). There is hence a clear segmentation of the labor market (Doeringer and Piore, 1971). The wage segmentation due to the dual system of entry seems however to disappear gradually over time (in Figure 1a, five years after entry, there are no more multiple modes). It thus appears that the majority of the individuals is only temporarily trapped in low wages.

These results are in line with the predictions of the "entry port hypothesis" and clearly support the "theory of career mobility". According to the "entry port hypothesis", youth contracts are transitional steps in the career trajectory and initial disadvantages are therefore likely to be overcome. In other words, the "entry port hypothesis" stresses the temporary character of the first job and assumes fast upward mobility and stabilization of the career (Contini et al., 1999). The "theory of career mobility" (Sicherman, 1991; Scherman and Galor, 1990) states that employees accept youth contracts because they offer better chances of more rapid promotion: that is, these positions serve as steppingstones for the future career. This implies greater upward mobility from these jobs than from permanent positions (where the employees would not be promoted as quickly). As a result, workers overcome their initial disadvantages. Note that Schizzerotto and Cobalti (1998) report that the Italian labor market is primarily structured by internal labor markets, which means that the career mobility model is more likely to apply: access to internal career ladders in this case is made possible via certain entry positions

\footnotetext{
${ }^{4}$ Very similar curves can be obtained considering only standard contracts (and, therefore, excluding youth contracts).
} 
(i.e. youth contract) and initial disadvantages are therefore likely to be overcome. We now move to the analysis of polarization to add empirical evidence supporting the above theory and in order to clarify the importance of mobility in the Italian labor market.

\section{Looking at the polarization of wages}

Since we find evidence of at least initial labor market segmentation, it is possible that looking at the degree of wage polarization may give more insights than simply looking at the inequality of wages. By polarization, we mean the extent to which the population is clustered around a small number of distant poles (Esteban and Ray, 1994). Therefore, the more polarized a labor market (i.e. in terms of wages) is, the more likely it seems that conflicts and social tensions can emerge. One may thus consider the labor market as an amalgamation of groups, where two workers belonging to the same group are "similar" while two workers from different groups are "different" with respect to a given set of characteristics. Thus, polarization is a matter of groups. Note that two key concepts define polarization: the degree of homogeneity within each group and the degree of heterogeneity across groups. In other words, high within-group homogeneity (that can be measured by low values of the within groups Gini index) is bound to increase polarization while clear differences between two groups (implying a high value of the between groups Gini index) will increase polarization and social tension. There is thus an important difference between the concepts of polarization and inequality: increased within-group internal homogeneity which reduces inequality is expected to raise polarization. Finally, note that it is better to focus on a small number of groups in order to localize the feelings of conflict and avoid the multilateral checks and balances that ease tension (Esteban, 2001).

Our empirical analysis starts from the observation that the working population is already structured into groups on the basis of, say, the gender, education, wage levels ( low paid / normal paid), type of contract, occupation, sector and firm size. We will give various measures of polarization, using these alternative definitions of groups. Note that the index of polarization we use may be viewed as measuring the difference between the inter-group alienation (i.e. between groups Gini index) minus the "loss of identification" with one's own group due to the existence of within group inequality (i.e. the within groups Gini index), such a difference being computed relative to the overall level of 
inequality in the distribution. Our measure of polarization is hence minimal when intergroup alienation is zero and within group inequality is maximal (in which case the polarization measure becomes equal to -1). Polarization is maximal when inter-group alienation is the greatest and within group inequality is zero (in which case the measure of polarization is equal to one). The index of polarization will thus take positive values whenever inter-group alienation is higher than within group inequality.

Polarization may vary over time and, as explained in Section 2, this change in polarization may be due either to a change in the distribution of wages (what is often called "structural mobility", see, Markandya, 1982 and 1984) or a change in individual ranks (often called "exchange mobility", see, Markandya, 1982 and 1984). Our aim is to analyze changes in the level of polarization over time in order to understand the possible origins of tensions and conflicts among individuals with the same potential seniority. In order words, we would like to check whether there is eventually a relationship between labor market segmentation and potential seniority. Table 3 reports the results of our analysis.

We start by considering two groups defined on the basis of their wages: first low paid workers versus workers with somehow a "normal" wage, second workers with a very wage versus the other workers, and third workers with a high wage versus the other workers. We define workers with a low (very low) wage those whose wage locates them among the lowest $20 \%(10 \%)$ of the wage distribution. The highly paid workers are the ones located among the upper $20 \%$ of the wage distribution. It appears that the distribution of wages at the time of entry into the labor market is the one with the highest degree of polarization when the two groups selected are highly paid versus the other workers. This is the only case where the measure of polarization is positive. This way of defining groups seems therefore to be the one which best identifies two groups, where each individual has a strong sense of identification with his/her own group. One may also observe that, whatever the way we define the groups, polarization increases when potential seniority increases. In other words, our results indicate an increase in the level of antagonism either between workers with a low wage and the remaining workers, as well as between workers with high wages and the other workers. These observations led us to move to the case where three groups are considered: those with a low wage, individuals with a normal level of pay and workers with a high wage. In the first stage, at the time of entry in the labor force, polarization is equal to 0.555 . But five year after entry, polarization increased by $11 \%$ (achieving the value of 0.616 ). This 
increase is partially due to wage changes (67\%), that is, to structural mobility, and partially (33\%) to changes in ranks (exchange mobility). Both components have the same signs and sum up to increase antagonism.

When looking at labor market segmentation on the basis of groups defined by their individual characteristics and first job attributes (see Table 3) we observe that the degree of segmentation (that is strictly connected with the level of polarization) varies over time. Polarization between male and female workers is quite low but it increases with seniority. There is a $9 \%$ increase in five years: note that here structural mobility increases polarization while exchange mobility decreases polarization. When making a distinction between individuals with a low and high level of education ${ }^{5}$ we observe that polarization decreases with seniority: structural mobility turns out to decrease polarization and it overcomes the opposite effect of exchange mobility. When the two groups of workers correspond to industry versus services workers, polarization is low but slightly increases with seniority $(+4 \%)$, mainly as consequence of structural mobility, since exchange mobility in itself reduces polarization. When workers working in small firms are compared with those working in medium or large firm, polarization is also low and it even decreases (by 5\%) with seniority, mainly as consequence of structural mobility wage changes.

The study of labor market segmentation on the basis of entry contracts and occupation is of special interest for reasons discussed previously. There is a positive level of polarization when workers hired with apprenticeship contracts are compared with other workers. This confirms what was mentioned before concerning labor market segmentation at the time of entry in the labor market. Note that in this case polarization decreases very quickly with seniority although it does not disappear completely. At the time of entry in the labor force, polarization is equal to 0.214 , while five years later it is equal to 0.044 , a decrease of $80 \%$. This huge decrease is mainly due to structural mobility and may be explained by the fact that at the end of apprenticeship, contracts are renewed at higher wages. Note that these results support the "entry port hypothesis" (previously mentioned), while no clear conclusion can be drawn concerning the validity of the "theory of career mobility". Finally, when comparing blue with white collar workers $^{6}$, we find a low degree of polarization but in this case polarization increases quickly with seniority. The rise in polarization (about 36\%) is mainly due to structural

\footnotetext{
${ }^{5}$ We use as proxy for education the age at the first job (low education if age $<=20$; otherwise)

${ }^{6}$ Excluding apprenticeship contracts.
} 
mobility. It thus appears that polarization linked to the existence of a dual entry labor market decreases with seniority while polarization related to occupation increases with seniority, but in both cases the main effect is that of structural mobility.

\section{Conclusion}

This paper is a first attempt to combine the analysis of wage (income) polarization with that of wage (income) mobility. Using the polarization index $P_{G}$ recently proposed by Deutsch et al. (2007) we showed that, when taking the identity of the individuals into account (working with panel data), a distinction could be made between a change over time in polarization that is the consequence of "structural mobility" (change over time in the overall, between and within groups inequality) and a change in polarization that is the sole consequence of "exchange mobility" (changes over time in the ranks of the individuals).

This approach was then applied to the 1985-2003 Work Histories Italian Panel (WHIP), an employer-employee linked panel database developed by the Italian Social Security administrative sources. This empirical investigation seems to have increased our understanding of labor market segmentation in Italy, whether the groups are defined on the basis of the individual wages or when they are derived from other criteria such as white versus blue collar workers. Additional work is certainly needed before we can definitively conclude that the concept of polarization is an important tool to analyze issues related to labor market segmentation. 
Figure 1. Frequency density functions

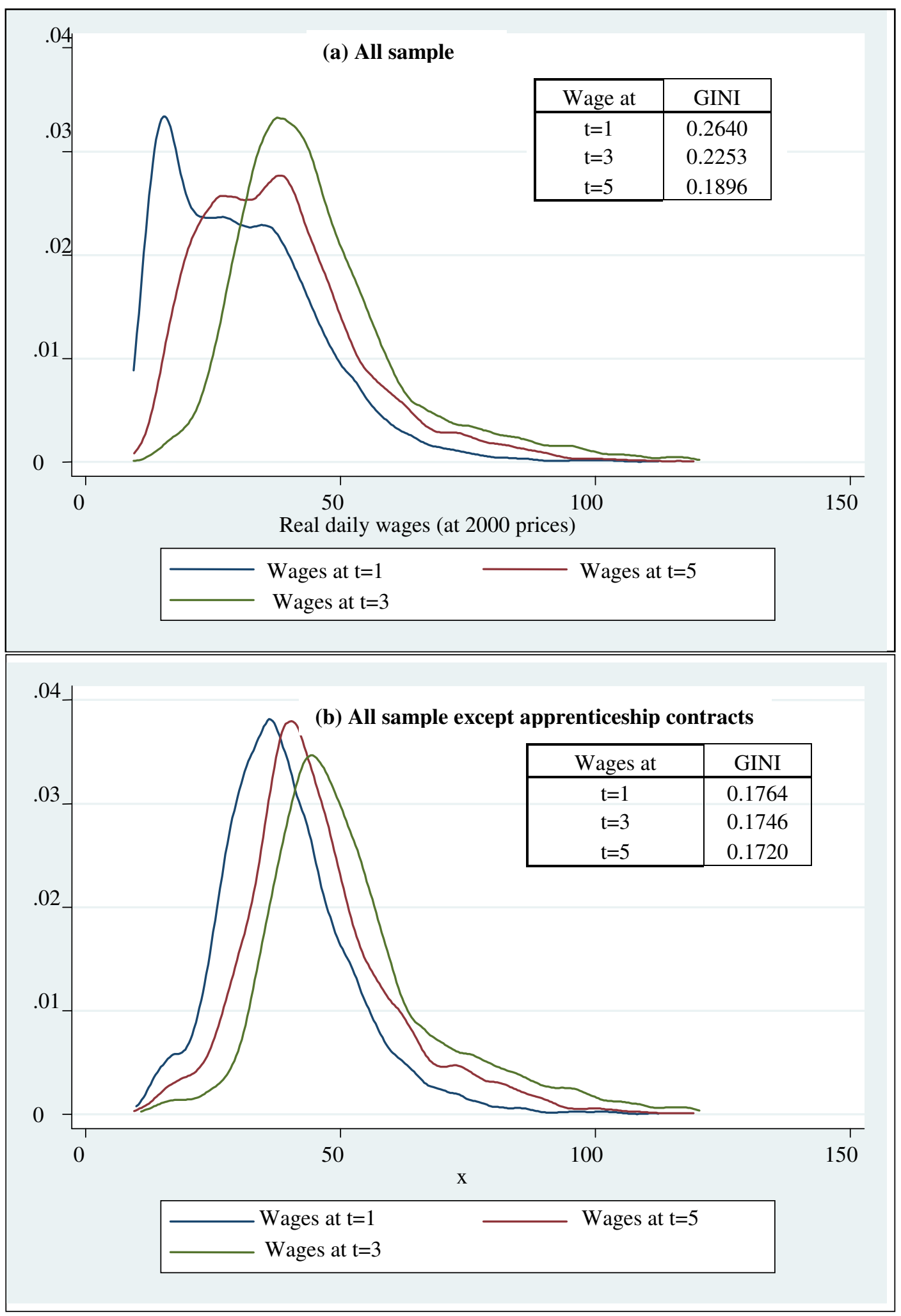


Table 1. Descriptive statistics

\begin{tabular}{|c|c|c|c|c|}
\hline Entry Characteristics: & \multicolumn{3}{|c|}{ Mean wage } & \multirow[t]{2}{*}{ Percentage } \\
\hline & $\mathrm{t}=1$ & $\mathrm{t}=3$ & $t=5$ & \\
\hline Males & 31.06 & 38.57 & 46.36 & 63.58 \\
\hline Females & 29.42 & 36.43 & 42.91 & 36.42 \\
\hline Low paid & 13.72 & 19.68 & 27.65 & 20.00 \\
\hline Medium paid & 28.81 & 36.01 & 42.64 & 60.00 \\
\hline High paid & 53.03 & 62.31 & 71.04 & 20.00 \\
\hline $\begin{array}{l}\text { Blue collars } \\
\text { White collars }\end{array}$ & & & & \\
\hline Entry contracts & & & & \\
\hline CFL & 37.80 & 41.30 & 41.31 & 21.53 \\
\hline Trainers & 18.86 & 24.58 & 30.58 & 42.47 \\
\hline Standard contracts & 39.84 & 45.75 & 51.89 & 36.00 \\
\hline Small (0-19 employees) & 29.10 & 36.84 & 43.91 & 64.12 \\
\hline Medium-Large firms & 38.67 & 46.19 & 53.36 & 35.88 \\
\hline Services & 34.11 & 42.00 & 49.15 & 35.84 \\
\hline Industry & 28.69 & 35.76 & 43.18 & 64.16 \\
\hline Low-Educated (**) & 23.81 & 31.46 & 39.15 & 67.22 \\
\hline High-educated & 44.62 & 51.40 & 58.03 & 32.78 \\
\hline Wage (daily) & 30.63 & 38.00 & 45.32 & 100.0 \\
\hline
\end{tabular}

Note: daily wage in Euro (2000)

$(* *)$ we use as proxy for education the age at the first job (low education if age $<=20$; otherwise)

Table 2. Wage inequality

\begin{tabular}{|c|ccccccccc|}
\hline $\begin{array}{c}\text { Potential } \\
\text { experience }\end{array}$ & GINI & GE(-1) & GE(0) & GE(1) & GE(2) & A(0.5) & A(1) & A(2) \\
\hline & & & & & & & & & \\
$\mathbf{t}=\mathbf{1}$ & 0.2640 & 0.1295 & 0.1139 & 0.1095 & 0.1150 & 0.0545 & 0.1077 & 0.2058 \\
$\mathbf{t}=\mathbf{3}$ & 0.2253 & 0.0905 & 0.0824 & 0.0811 & 0.0863 & 0.0401 & 0.0791 & 0.1533 \\
$\mathbf{t}=\mathbf{5}$ & 0.1896 & 0.0611 & 0.0585 & 0.0599 & 0.0655 & 0.0291 & 0.0568 & 0.1088 \\
\hline
\end{tabular}

Note: GE refer to generalized entropy indices and A to the Atkinson index. 


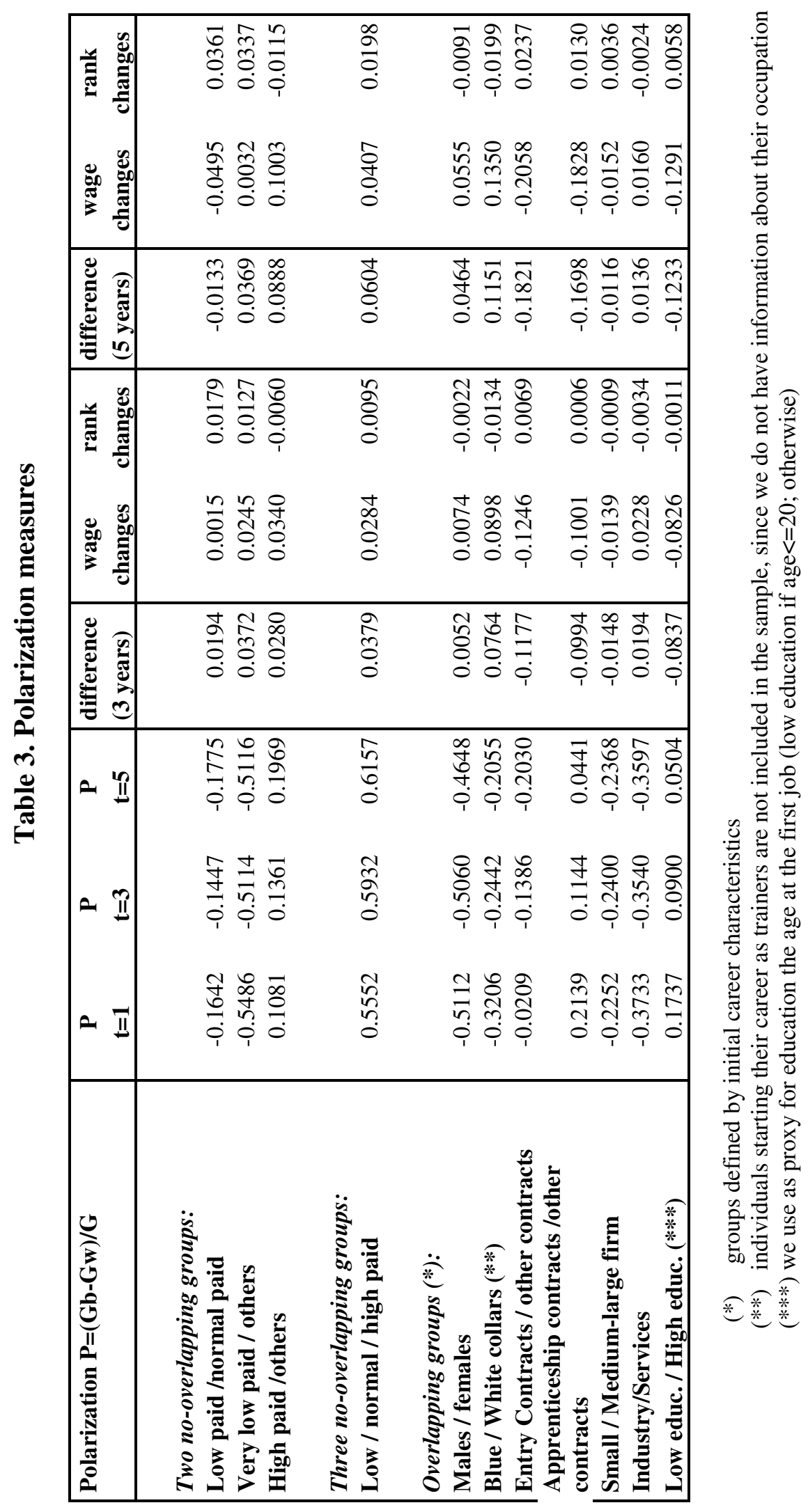




\section{References}

Contini, B., L. Pacelli and C. Villosio (1999) "Short employment spells in Italy, Germany and Great Britain: testing the "port-of-entry" hypothesis", CEP Working Papers, London: Graham Igham.

Deutsch, J., M. Hanoka and J. Silber (2007) "On the Link Between the Concepts of Kurtosis and Bipolarization," Economics Bulletin, 4(36): 1-6.

Deutsch, J. and J. Silber (2008a) "Analyzing the Impact of Income Sources on Changes in Polarization," mimeo.

Deutsch, J. and J. Silber (2008b) "On the Decomposition of Income Polarization by Population Subgroups", mimeo.

Doeringer, P. B. and M. J. Piore, M. (1971) Internal Labour Markets and Manpower Analysis, Lexington, KY: DC Heath and Company.

Esteban, J.M. and Ray, D. (1994) “On the measurement of polarization”, Econometrica, 62, pp. 819-852.

Esteban, J.M. (2001) "Economic polarization in the Mediterranean Basin: an introduction to the notion and measurement of polarization", mimeo.

Markandya, A. (1982) "Intergenerational Exchange Mobility and Economic Welfare", European Economic Review 17: 307-324.

Markandya, A. (1984) “The Welfare Measurement of Changes in Economic Mobility”, Economica 51: 457-471.

Sicherman, N. (1991) ““'Overeducation” in the Labor Market”, Journal of Labour Economics 9: 101-23

Scherman, N. and Galor, O. (1990) "A theory of career mobility", Journal of Political Economy 98: 169-92

Schizzerotto, A., and Cobalti, A. (1998) "Occupational returns to education in contemporary Italy", in Y. Shavit and W. Muller (eds) From school to work: a comparative study of educational qualifications and occupational destinations, pp. 253-86, Oxford: Oxford University Press.

Silber, J. (1989) "Factors Components, Population Subgroups and the Computation of the Gini Index of Inequality," The Review of Economics and Statistics LXXI:107-115. 